\title{
The Proper Limits of Secrecy
}

$7 \mathrm{HE}$ costs of secrecy are high. When the freedom of sci1 entific exchange is curtailed, an unfavorable reaction upon further scientific development is inevitable. We pay for secrecy by slowing the rate of our scientific progress, now and in the future. This loss of momentum may conceivably be disastrous, for even from the strictly military point of view "it is just as important for us to have some new secrets to keep as it is for us to hold on to the old ones." 1 If it is unsound to suppress scientific knowledge during the long years of a cold war, the American people may one day discover that they have been crouching behind a protective wall of blueprints and formulas whose impregnability is an utter illusion.

On the other hand, no one can argue that national safety should be ignored by carefree revelation of military secrets. Surprise is an important element of a new weapon, because it reduces the likelihood of countermeasures and thus enhances the effectiveness of the development when it is first utilized. Moreover, concealment of the fact that researches are in progress may be important simply to avoid identifying the areas in which the United States does not deem itself adequately prepared. So it is plain that silence may in itself have military advantage even in connection with the more or less 
conventional instruments of warfare like the bazooka, the long-range bomber, and the rocket. When one's mind turns from customary military tools to the more recent engines of catastrophe such as the H-bomb, the germ invasion, and the atomic explosion, one feels even more strongly that silence may be worth its steep costs.

Can these conflicting concerns be reconciled? Is it possible to disseminate the knowledge that will lead to more knowledge, while at the same time giving respect to the military considerations just suggested?

Reconciliation is possible if an effort is made to clarify the line between scientific data and military applications of those data.

Few of the real "secrets" which this country possesses are formulas or principles beyond the grasp of others. The real secrets, chiefly, are the mechanics by which a laboratory theory is translated into a large-scale operation. The distinction is well brought out by Sir Alexander Fleming's recent reminiscence concerning the development of penicillin. While working on an entirely different problem, he chanced one day to note the extraordinary effect of a stray mould on a culture of bacteria it had contaminated. "I worked out some of the properties of Penicillin," Sir Alexander said, "and went as far as I could as a bacteriologist, but I got completely stuck because anything we did to concentrate the Penicillin which the mould produced in its culture destroyed the activity . . .

"Things remained latent from 1929 when I described Penicillin until 1939 when Florey and Chain and their colleagues set out to make a systematic study of the antibiotics which had been described. At that time I understand that they had forgotten Penicillin, but Chain, reading the literature, came across my description of it and thought something could be done chemically. They got a team together and they succeeded in concentrating the active principle about 1,000 times. This 
concentrate they could preserve by freeze drying so they were able to accumulate a stock sufficient to test the therapeutic efficiency first on mice and then on men.

"From the first trials there was no doubt about its efficacy but then came the question of mass production during the war. The Oxford team had shown that it could be done, but this was a vastly different thing from producing it in bulk, and it was only by international co-operation of governments, scientists, industrialists, engineers and everyone down to the lowest grade workman that the production of Penicillin on a large scale was accomplished." 2

The difficulty of translating a principle into a process has been succinctly illustrated, too, by a distinguished physical chemist. "Every boy who has had high school physics," writes Professor Frank Spedding, "knows the principles of the electric generator but this is a long way from being able to manufacture a 50,000 kilowatt generator such as is used at Niagara Falls. Here the real secret is in the technical know-how of how to produce this generator, and this secret is spread among many individuals in many professions such as miners, metallurgists, electrical engineers, chemists, physicists, etc.; no single man, if he wished, could give away the entire secret. So it is, to a much greater extent, with the so-called secret of the atomic bomb." 3

The difference between knowledge and know-how is indeed exemplified by some of the processes which lead to the production of fissionable material in large quantities. One of the methods employed to separate U-235 from other uranium isotopes is gaseous diffusion, that is, forcing a gas against a series of metal membranes and capturing the lighter isotopes which first pass through the minute openings in these porous barriers. The understanding of the theory and mechanics of gaseous diffusion dates back to the work of, among others, Lord Rayleigh in England in 1896. But England and 1896 
are a far cry from "K-25," the mile-long gaseous diffusion plant in Tennessee where uranium hexafluoride is cycled through some four thousand barriers in what is said to be the largest continuous operation under one roof any place in the world. One may doubt that Lord Rayleigh himself could have envisioned or designed "K-25."

Should we, then, seek to make a distinction between basic science and technology? Should we, in short, suppose that free trade in fundamental ideas will ensure the growth of science, while, on the other hand, guarding the details of our elaboration and effectuation of those ideas will ensure our national safety?

This differentiation is difficult to maintain systematically. The basic and therefore hypothetically innocuous science cannot readily be disentangled from the rest. As has already been observed, the forward movement of scientific achievement rarely depends upon a single flash of genius; rather, it is a consequence of the slow weaving together of many strands. Advance is built upon a selective amalgamation of the work of others, and often it is the failure or the practical limitations of one effort which suggest a fresh and finally successful approach. The realities of engineering and chemical processes frequently set the limits within which general ideas can function beneficially, with the possibility that they will stimulate still more ideas.

Nor, unless the claims of civilization are to be ignored, can the sole test of publishability of scientific work be its possible utilization in military research. Professional communication was successfully blockaded on a short-term basis during a period of active strife, and no one suffered seriously as a consequence. This does not establish that scientific freedom can or should be restrained over a span of many years. Previous pages have described the gradual and undramatic devitalization that is an inescapable concomitant of secrecy. Let us 
now add that abatement of scientific publication because of prolonged international tension would also entail the rigid suppression of discoveries which have great and immediate value to society in peacetime. We live, after all, in peace, not war-an uneasy peace, to be sure, and one shaken by events in Korea, but peace nevertheless. A total war may never come. All humanity prays that it will not. If mankind's intelligence is equal to the task of preserving mankind's existence, largescale resort to arms will not occur. We must be certain that the hypothetical enhancement of martial advantage in the future is not permitted wholly to obscure the discernible enhancement of human well-being in the present.

Reference to recent developments in biological warfare research will illustrate the choice that lies open.

Since 1942, when an organization cryptically called the War Research Service began its labors, our country has actively supported investigations looking toward perfection of offensive and defensive measures for use in biological (or "bacterial" or "germ") warfare. In 1943 Camp Detrick in Maryland was set aside as the main center of work in this field, which is now under the jurisdiction of the Chemical Corps of the Department of the Army. There is no doubt about the goals of the biological warfare $(\mathrm{BW})$ project, though the current operations of Camp Detrick are conducted behind an opaque wall of secrecy. "Our endeavors during the war," according to George W. Merck, the chairman of the United States Biological Warfare Committee, "provided means of defending the nation against biological warfare in terms of its presently known potentialities and explored means of retaliation which might have been used had such a course been necessary . . Work in this field, born of the necessity of war, cannot be ignored in time of peace; and it must be continued on a sufficient scale to provide an adequate defense." To this end large sums of money and the efforts of literally 
thousands of persons have been devoted; their purpose has been "to extend the boundaries of knowledge concerning the use of pathogenic agents as a weapon of war and the means of protection against possible enemy use of these agents." 4

Obviously enough, every phase of the work at Camp Detrick has military significance. If any bit of it is revealed, other nations interested in biological warfare, including potential enemies, will benefit. They will be saved time and expense in discovering infective agents and counter actions against them. They will be spared the necessity of making the same false starts that probably marked our efforts.

These circumstances, however, do not entirely offset the disadvantages of nondisclosure. The Merck Report tells us that intensive investigations were carried out at Camp Detrick into "the effectiveness of antibiotics and chemotherapeutic agents" and into "biological, physical and chemical protective measures" against "various organisms of high diseaseproducing power." Can we afford to keep our epidemiologists and our general practitioners unaware of the results of these activities, as we must do if our thoughts dwell exclusively on military implications? The infective agents that may be used against man in the course of BW are agents which, after all, may infect him in peacetime as well. Again, the Merck Report makes clear that extensive study was made of "biological and chemical agents which might have been used in attacking our crops," and that this "resulted in certain discoveries which will undoubtedly prove of great value to agriculture." In a dynamic economy like ours, would it be wise to ignore the "great value to agriculture" because those "certain discoveries" may also be of great value to military planners?

The intertwining of interests, the civilian and military, is nowhere more clearly apparent than in the official summary of the more important accomplishments of the Biological Warfare program up to 1946 . No matter how scant may be one's 
knowledge of bacteriology or of the waging of war, one cannot fail to perceive that every item of the following list has potentially great significance for public health, industry, and agriculture as well as for BW:

1. Development of methods and facilities for the mass production of micro-organisms and their products;

2. Development of methods for the rapid and accurate detection of minute quantities of disease-producing agents;

3. Significant contributions to knowledge of the control of airborne disease-producing agents;

4. Production and isolation, for the first time, of a crystalline bacterial toxin, which has opened the way for the preparation of a more highly purified immunizing toxoid;

5. Development and production of an effective toxoid in sufficient quantities to protect large scale operations should this be necessary;

6. Significant contributions to knowledge concerning the development of immunity in human beings and animals against certain infectious diseases;

7. Important advances in the treatment of certain diseases of human beings and animals, and in the development of effective protective clothing and equipment;

8. Development of laboratory animal propagation and maintenance of facilities to supply the tremendous number of approved strains of experimental animals required for investigation;

9. Application of special photographic techniques to the study of airborne micro-organisms and the safety of laboratory procedures;

10. Information on the effects of more than 1,00o different chemical agents on living plants; 
11. Studies of the production and control of certain diseases of plants. ${ }^{5}$

Since January 1946 about $\mathbf{1 6 0}$ papers and monographs embodying $\mathrm{BW}$ researches have been published. The fact that these materials are available for general use reflects enlightened awareness by the Army that the science of peace and the science of war have many common interests. Dr. Rosebury in his excellent book, Peace or Pestilence, has traced the value of these reports for "healthy science." " Camp Detrick studies on synthetic plant-growth regulators have provided tools to aid in basic research into "the nucleus which dominates the activities of the living cells." The crystallization of botulinus toxin, an unprecedented accomplishment, is likely to spur the final isolation of other bacterial toxins and has "put in the hands of the chemist powerful tools for exploring some of the basic problems of disease." Study of viruses that produce animal diseases has yielded new methods for recognizing them promptly as well as effective vaccines for protection against them. ${ }^{7}$ The steps taken at Camp Detrick to control accidental airborne infections "have proved valuable not only in research with highly infective agents there and elsewhere but also in work that requires the exclusion of germs, as in the commercial production of biologicals like liver extracts, which must be handled in a germ-free environment because they are damaged by any attempt to sterilize them with heat or chemicals." The BW experiments on infection carried through the air "have also made available exact methods and refined techniques to attack the most important group of human diseases still uncontrolled by sanitation-the respiratory infections, like influenza and tuberculosis."

The catalog of positive advances made possible by biological warfare research is far from exhausted by these instances, which in any event deal only with immediately foreseeable 
benefits. These discoveries, like other fundamental data, are likely to be of yet further help in ways which no one can as yet know. The given instances sufficiently suggest, however, that a publication policy that adhered strictly to a "guns instead of butter" philosophy would have deprived the nation of a very considerable amount of butter, indeed. The social costs of secrecy are readily seen here, just as they would be if the researches of our agronomists and animal husbandrymen were to be "classified" for fear that a potential enemy might use them to increase its food resources.

When one turns to industrial applications of military researches, the choices become less plain because they are not colored by moral convictions regarding human health. Even so, there is cause for concern in the fact that American industrial efficiency has not been given as much consideration as perhaps it deserves. For instance, there has not yet been full publication of the information gained by the National Defense Research Committee concerning the behavior of materials under strain and pressure. Fundamental knowledge acquired through studies of the various reactions occurring when a gun is fired would have significance for highcompression technology generally. During the war American scientists developed a machinable metal, "Alloy X," which possesses remarkably high strength, moderate ductility, and hot-hardness and is thought to be capable of numerous future applications. But because the erosion-resistant qualities of Alloy X make it useful for lining the barrels of high-velocity guns, even the basic metal from which it was evolved is still a secret withheld from American metallurgists. ${ }^{8}$ If military purposes are thought to be advanced by suppressing knowledge of these sorts of scientific finds, we should at least be aware that suppression does not contribute to an ever more abundant economy.

If, then, a general proposition may be suggested, it is this: 
Secrecy ought not to be readily attached to scientific or technological matters merely because in some aspects they have military significance. It should be attached unhesitatingly if their sole significance is a military one. Application of this differentiation may be clarified by referring to the several fields of earlier discussion.

Much Biological Warfare research, for example, has been released, but, notwithstanding a generally liberal publication policy, a great deal remains steeped in secrecy. Despite the Merck Report's assurance that Camp Detrick developed "methods for the rapid and accurate detection of minute quantities of disease-producing agents," no details concerning those methods have yet been reported. This seems an indefensible exaltation of military values over human needs. On the other hand, suppression of reports concerning the containers developed for disseminating infectives seems entirely justified. There is no discernible civilian need for specially constructed devices for spreading pathogenic agents, which have been aptly characterized as "BW munitions." They constitute part of the secret techniques of war rather than part of the lifeenriching treasury of science. If they remain secret and unrevealed forever, mankind will be the gainer rather than the loser.

The Atomic Energy Commission has refused to declassify a research report on the effects of exposure to a certain chemical compound, because the report was written at Los Alamos and the inference might therefore be drawn that the chemical in question is used in connection with bomb manufacture. Similarly, at the Argonne National Laboratory a report of experiments on the properties of certain uranyl salts was placed under restriction, apparently because the experimenters had suggested that their study might possibly shed light on the separation of uranium isotopes as well as other chemical processes. Suppression of these types of knowledge seems of doubt- 
ful wisdom. They may be importantly useful in the planning of industrial operations or in the conduct of researches wholly unrelated to the production of bombs. By way of contrast, chemical research during the war made possible the perfection of unorthodox hand devices and techniques of sabotage for use by guerrilla and resistance forces, looking toward maximum destruction of enemy personnel and property. Most of the weapons produced for this purpose were simple in design and were chiefly of an explosive or incendiary nature. Unfortunately the unconventional devices that were created for field use during the war are suitable for employment by lawless, terroristic, or subversive elements in time of peace as well. The knowledge embodied in these weapons is so unlikely to have legitimate application that continued restrictions upon its publication are fully warranted. ${ }^{9}$

A distinction must properly be drawn between, say, information concerning neutron cross sections of the heavy metals (which, being valuable for further physical research, ought to be revealed) and information concerning the design or mechanism that prevents premature disintegration of an atomic bomb before it has efficiently utilized its charge of fissionable material (which, being essentially a military device, may properly be concealed). A distinction must be drawn between, on the one hand, a new understanding of aerodynamics and, on the other, the plans of a specific military aircraft that undertakes to utilize the new understanding. In short, the design of weapons, reports about their performance and properties, the design of large-scale plants for their production, and, occasionally, specific instruments or processes can be kept under flexible restrictions without any very likely effect upon industrial or scientific advance. But care must be exercised to avoid confusing these matters with principles and practices which expand the edges of understanding and which may be pieced together with other bits of knowledge for the 
well-being of mankind. While it is true that the latter may conceivably benefit a potential enemy in some particular, the risk of that benefit is more bearable than the sapping of our own strength.

It would be unfair to suggest that this commonsensical conclusion has been beyond the grasp of our nation's military and atomic energy authorities. Quite to the contrary, there is every reason to believe that existing basic policies are not inharmonious with it.

Unfortunately, however, the effectuation of those policies has been retarded by two forces. One is the force of official inertia, the reluctance to exercise judgment incisively and boldly, the unwillingness to accept responsibility for disclosing information which a later critic may maintain should have remained secret. ${ }^{10}$ The other is the force of a badly misled public opinion.

Enlightenment of popular sentiment is difficult so long as political leaders violently denounce the imparting of knowledge as though it were a plot to advance the fortunes of Soviet Russia. Both the Atomic Energy Commission and the services have occasionally manifested readiness to lower the barriers which decelerate scientific progress and which block public understanding of giant governmental efforts to enlarge our resources. ${ }^{11}$ Their inclinations in this respect are not stimulated by criticisms such as those addressed to the AEC by a distinguished Senator, who deplored the AEC's reproduction of a photograph of the outside of a small model of the Brookhaven proton-synchrotron ("or some such thing"), a nonsecret research tool, or a prominent Representative's perturbation that the AEC had revealed that Brookhaven has a 420 -foot tall tower that emits smoke "which can sometimes be seen for miles around." ${ }^{12}$ If secrecy is permitted to become a fetish, rational judgments lose their relevance.

The hope for science in this country and for the nation's 
security is that the public at large will shed its fears, grow in understanding, and cease credulously accepting assertions that safety lies in secrecy. Secrecy is antithetical to the spirit of science. ${ }^{13}$ It is socially hurtful. Only for brief periods can it be practiced without destroying the scientific superiority it is intended to preserve. Today the United States holds a position of dominance in world science largely because of its rich resources of technical and scientific manpower, coupled with material facilities that cannot be duplicated by the impoverished countries of Europe and the Orient. Unless this country dissipates its advantages by artificially limiting what the rising generation of scientists may be permitted to learn, its strong ranks of talented, well-trained humans rather than its possession of a body of knowledge are probably the chief guarantor of America's future leadership. 